\title{
PERANAN CIEF ENGINEER DALAM MENINGKATKAN PRODUKTIFITAS KERJA DI ENGINE ROOM PADA MT. GRIYA FLORES
}

\author{
Victor Wiku Widyo Bharoto $^{1 *}$, Budi Purnomo ${ }^{2 *}$, Puryadi $^{3^{*}}$ \\ ${ }^{1,2 \& 3}$ Program Studi Teknika, Fakultas Teknik, Politeknik Bumi Akpelni \\ Jl. Pawiyatan Luhur II/17, Bendan Dhuwur, Semarang \\ email:tirtasamudera79@gmail.com
}

\begin{abstract}
Abstrak
Tujuan penelitian ini adalah untuk menganalisis seberapa jauh peran dari Cief Engineer dalam meningkatkan produktivitas kerja dikapal terutama pada bagian mesin. Teknik pengumpulan data dilakukan berdasarkan pengamatan langsung dilapangan ketika penulis bekerja menjadi masinis diatas kapal tanker MT.Griya Flores milik dari PT.Humpuss Transportasi Kimia - Jakarta Selatan. Adapun pengamatan yang dilakukan antara lain: Melakukan pengamatan secara langsung kondisi diatas kapal khususnya dikamar mesin saat penulis berada diatas kapal. Penulis juga melakukan pencatatan dan monitoring langsung kinerja dari Kepala Kamar Mesin dan beberapa perwiral mesin kapal dan beberapa data. Mengingat begitu banyak masalah yang timbul dalam pembahasan penelitian, penulis membatasi lingkup bahasan permasalahan ini khususnya hanya pada masalah organisasi dan administrasi personal pada MT. Griya Flores Untuk lebih memudahkan pembahasan masalah setelah diidentifikasi masalahnya, maka dilaksanakanlah pemilihan masalah sesuai USG, adapun USG itu sendiri adalah sebagai berikut (Urgency adalah masalah yang apabila tidak segera diatasi akan berakibat fatal dalam jangka waktu panjang. (Seriousness) adalah masalah yang apabila terlambat diatasi akan berdampak fatal terhadap kegiatan tetapi berpengaruh pada jangka pendek. (Growth) Adalah masalah potensial untuk tumbuh dan berkembangnya masalah dalam jangka panjang dan timbulnya masalah baru dalam jangka panjang. Identifikasi Masalah Bahwa sehubungan dengan produktivitas kerja yang rendah penulis telah mengidentifikasi beberapa masalah, antara lain Timbulnya Kejenuhan Kerja Perbedaan latar belakang budayaAkibat perbedaan bahasa, SDM Kurang terampil ,Kurangnya disiplin kerja membuat ABK mesin terampil agar operasional kapal lancar. Peranan tugas dan tanggung jawab Cief Engineer yang berlaku di lingkungan perusahaan dalam meningkatkan kelancaran operasional kapal, Peningkatan keterampil ABK mesin dalam Bekerja, Menegakkan disiplin kerja Disarankan kepada seluruh perwira di atas kapal untuk meningkatkan kemampuan manajemen, agar supaya dapat mengatasi setiap permasalahan yang bersangkutan dengan kerja di kamar mesin, sehingga produktifitas kerja dapat dicapai semaksimal mungkin.Untuk mempromosikan seorang masinis untuk menduduki jabatan yang lebih tinggi, sebaiknya tidak hanya mempertimbangkan ijazah yang dimiliki tetapi juga mempertimbangkan pengalaman kerja diatas kapal, serta prestasi selama kerja. Cief engineer sebagai pimpinan tertinggi di Engine room agar lebih mendalami masalah manajemen dan kepemimpinan yang baik agar dapat membimbing dan mengayomi anak buah kamar mesin.
\end{abstract}

kata kunci : peranan, cief engineer, engine room.

\section{PENDAHULUAN}

\section{Latar Belakang}

Salah satu faktor yang perlu mendapat perhatian dalam perusahaan pelayaran agar bisa bersaing yaitu aktifitas intern organisasi perusahaan. Untuk itu diperlukan kecakapan manajemen dalam mengelola perusahaan. Adapun upaya yang dapat dilakukan dalam membenahi organisasi intern perusahaan yaitu dengan membenahi sistem organisasi intern yang tepat didalam perusahaan, dengan jalan meningkatkan efisiensi kerja dengan disiplin yang berdasarkan pada specialisasi tugas, dinilai dapat menciptakan sinergi. Dengan meningkatkan efisiensi dan disiplin dalam kerja ini diharapkan permasalahan yang terjadi dapat diatasi dan diselesaikan dengan baik. Dalam usaha mencapai kelancaran operasional kapal, diperlukan manajemen yang baik di kamar mesin. Dalam hal ini cief engineer selaku pimpinan di kamar mesin dituntut untuk senantiasa bekerja secara maksimal. Untuk mencapai tujuan tersebut cief engineer harus mengatahui segala permasalahan yang terjadi di kamar mesin 
termasuk didalamnya kemampuan/ ketrampilan Masinis dalam menjalankan tugas dan tanggung jawabnya. Dengan kata lain Cief Engineer dalam menjalankan tugasnya harus memotivasi apa yang dilakukan para masinis dan bawahan lainnya. Perlunya Cief Engineer memberi pengarahan dan motivasi yang efektif terhadap anggota kamar mesin dengan berkomunikasi, melatih dan mengembangkan kreatifitas mereka, berkonsultasi dan sebagainya. Dengan demikian sebelum menjalankan tugasnya, ada beberapa hal yang harus dikuasai oleh seorang Cief Engineer antara lain :

1. Perencanaan

2. Pengorganisasian

3. Pengkoordiniran dalam bidang kepemimpinan

4. Mengarahkan penyelidikan terhadap lapangan pengetahuan dan tambahan, terutama yang berhubungan dengan manajemen, psikologi dan lain-lain.

Sehingga yang menjadi masalah pokok dalam penelitian ini adalah sumber daya manusia yang masih kurang profesional dapat teratasi. Berdasarkan uraian di atas maka penulis tertarik untuk mengambil judul "Peranan Cief Engineer dalam Meningkatkan Produktivitas Kerja di Kamar Mesin Pada MT. Griya Flores.

\section{Pokok Permasalahan}

Berdasarkan uraian di atas maka permasalahan yang akan dibahas ialah: Bagaimana peran dari Cief Engineer dalam meningkatkan produktivitas kerja bagian mesin.

\section{Tujuan Dan Manfaat Penulisan}

Tujuan penelitian ini untuk mengetahui seberapa jauh peran dari Cief Engineer dalam meningkatkan produktivitas kerja dikapal terutama pada bagian mesin. Manfaat penulisan penelitian bagi penulis sendiri dan kawan-kawan seprofesi dalam usaha mengembangkan dan meningkatkan profesionalisme, agar mempunyai wawasan yang berkemampuan secara ilmiah professional bertingkat manegerial. Sedangkan manfaat bagi perusahaan untuk memberi sumbang saran agar hal-hal yang tidak diinginkan dalam operasional kapal dapat dihindari minimal dikurangi.

\section{Lingkup Bahasan}

Mengingat begitu banyak masalah yang akan timbul dalam pembahasan karya ilmiah ini, penulis membatasi lingkup bahasan permasalahan ini khususnya hanya pada masalah organisasi dan administrasi personal pada MT.GRIYA FLORES milik perusahaan HUMPUSS JAKARTA

\section{METODE}

Metode yang digunakan dalam penelitian ini adalah statistic desskriptif

\section{LANDASAN TEORI}

\begin{tabular}{lrr}
\multicolumn{1}{c}{ Untuk lebih memudahkan } \\
pembahasan & masalah & setelah \\
diidentifikasi & masalahnya, maka \\
dilaksanakanlah pemilihan masalah sesuai \\
USG, adapun USG itu sendiri adalah \\
sebagai berikut:
\end{tabular}




\begin{tabular}{|c|c|c|c|c|c|c|c|c|c|c|}
\hline \multirow[t]{2}{*}{ No } & \multirow[t]{2}{*}{ Masalah } & \multirow{2}{*}{$\begin{array}{l}\text { Analisa } \\
\text { Perbandingan }\end{array}$} & \multirow[t]{2}{*}{$\mathrm{U}$} & \multirow[t]{2}{*}{$\mathrm{S}$} & \multirow[t]{2}{*}{$\mathrm{G}$} & \multicolumn{4}{|c|}{ Nilai } & \multirow[t]{2}{*}{ Prioritas } \\
\hline & & & & & & $\mathrm{U}$ & $\mathrm{S}$ & $\mathrm{G}$ & $\mathrm{T}$ & \\
\hline $\mathrm{A}$ & $\begin{array}{l}\text { Timbulnya } \\
\text { Kejenuhan } \\
\text { Kerja }\end{array}$ & $\begin{array}{l}\text { A-B } \\
\text { A-C } \\
\text { A-D } \\
\text { A-E }\end{array}$ & $\begin{array}{l}\text { A } \\
\text { A } \\
\text { D } \\
\text { E }\end{array}$ & $\begin{array}{l}\text { A } \\
\text { C } \\
\text { D } \\
\text { E }\end{array}$ & $\begin{array}{l}\text { A } \\
\text { A } \\
\text { D } \\
\text { E }\end{array}$ & 2 & 1 & 2 & 5 & III \\
\hline B & $\begin{array}{l}\text { Perbedaan } \\
\text { latar belakang } \\
\text { budaya }\end{array}$ & $\begin{array}{l}\text { B-C } \\
\text { B-D } \\
\text { B-E }\end{array}$ & $\begin{array}{l}\text { C } \\
\mathrm{D} \\
\mathrm{E}\end{array}$ & $\begin{array}{l}\text { C } \\
\mathrm{D} \\
\mathrm{E}\end{array}$ & $\begin{array}{l}\mathrm{B} \\
\mathrm{D} \\
\mathrm{E}\end{array}$ & 0 & 0 & 1 & 1 & V \\
\hline $\mathrm{C}$ & $\begin{array}{l}\text { Akibat } \\
\text { perbedaan } \\
\text { bahasa. }\end{array}$ & $\begin{array}{l}\text { C-D } \\
\text { C-E }\end{array}$ & $\begin{array}{l}\mathrm{D} \\
\mathrm{E}\end{array}$ & $\begin{array}{l}\mathrm{D} \\
\mathrm{E}\end{array}$ & $\begin{array}{l}\mathrm{D} \\
\mathrm{E}\end{array}$ & 1 & 2 & 0 & 3 & IV \\
\hline $\mathrm{D}$ & $\begin{array}{l}\text { SDM } \\
\text { Kurang } \\
\text { terampil } \\
\end{array}$ & D-E & $\mathrm{D}$ & $\mathrm{D}$ & $\mathrm{D}$ & 4 & 4 & 4 & 12 & I \\
\hline$E$ & $\begin{array}{l}\text { Kurangnya } \\
\text { disiplin kerja }\end{array}$ & & $\mathrm{E}$ & $\mathrm{E}$ & $\mathrm{E}$ & 3 & 3 & 3 & 9 & II \\
\hline
\end{tabular}

(Urgency) : adalah masalah yang apabila tidak segera diatasi akan berakibat fatal dalam jangka waktu panjang. (Seriousness) : adalah masalah yang apabila terlambat diatasi akan berdampak fatal terhadap kegiatan tetapi berpengaruh pada jangka pendek. (Growth)

: Adalah masalah potensial untuk tumbuh dan berkembangnya masalah dalam jangka panjang dan timbulnya masalah baru dalam jangka panjang.

Alternatif Memilih Prioritas Masalah Untuk Analisis Penyebab Teori Usg Keterangan :

- 1 = Sangat penting

- 2 = Penting

- $3=$ Tidak terlalu penting

$-4=$ Tidak penting

- $5=$ Sangat tidak penting

\section{Keadaan Yang Diharapkan}

\section{Keterampilan ABK Mesin Cukup Baik}

Pada bagian mesin di atas kapal, pemimpin tertinggi berada di tangan Cief Engineer. Sebagai pimpinan harus selalu berusaha untuk bekerja dengan sebaikbaiknya sebagai wujud tanggung jawab yang telah dipercayakan perusahaan kepadanya. Untuk menjalankan wewenangnya Cief Engineer dibantu para masinis dan bawahan lainnya.

Untuk mendapatkan kelancaran dalam operasional kapal Cief Engineer dituntut untuk merencanakan, mengorganisir dan mengkoordinasikan para bawahannya untuk bekerja secara cakap dan terampil. Disini tentunya diperlukan sikap demokratis Cief Engineer berdasarkan desentralisasi kekuasaan dan pengambilan keputusan, sebagai contoh ia senantiasa berkonsultasi dengan para bawahan mengenai berbagai permasalahan, tujuan dan tugas-tugasnya serta mendorong dan memanfaatkan bakat serta kemampuan para bawahan sepenuhnya. Sebagai hasil dari sikap demokrasi Cief Engineer maka para masinis dan bawahan lainnya mencapai ukuran hak milik dan pengetahuan yang besar dan cakap dalam kinerja yang 
memberikan motifasi kepada para masinis untuk meraih efisiensi yang lebih tinggi.

\section{Disiplin kerja diterapkan dengan baik}

Disiplin kerja dapat diterapkan dengan baik untuk mencapai kelancaran operasional kapal, untuk itu seorang Cief Engineer dituntun untuk bersikap adaptif atau pandai menyesuaikan diri dan luwes, misalnya karena dalam suatu kapal tidak semua masinis dan bawahan lainnya memiliki watak yang sama, hal tersebut dipengaruhi oleh antara lain latar belakang yang berbeda juga tingkat pendidikan. Disini dituntut untuk dapat menyatukan pendapat antara para masinis dalam menyelesaikan suatu tugas dengan baik melalui peningkatan disiplin untuk kelancaran operasional kapal.

Berdasarkan tugas dan fungsi dari masing-masing Masinis dalam masalah perencanaan kerja Cief Engineer dibantu oleh Masinis I. Dimana rencana kerja disusun berdasarkan jam kerja sesuai buku petunjuk mesin atau bisa juga berdasarkan laporan dari para masinis sesuai dengan tugas dan tanggung jawab masing-masing.

\section{Komunikasi lancar}

Akibat kurang lancarnya komunikasi antara atasan dan bawahan, maka seorang Cief Engineer hendaknya menulis perintah/informasi dipapan tulis setiap menyampaikan perintah/informasi kepada bawahan. Komunikasi bisa dilakukan secara lisan dan tulisan namun lancar.

\section{Hambatan-hambatan ABK Mesin kurang terampil}

Pada saat kapal dalam pelayaran antara pelabuhan sorong dan Pelabuhan Dobo Pada saat itu jam jaga Masinis II yaitu jam 00.00 - 04.00 telah terjadi kerusakan pada salah satu motor bantu, yaitu pompa pendingin air tawar tekanannya jatuh, Masinis II sebagai Masinis jaga, mengambil tindakan menjalankan motor bantu yang lain, sedang motor bantu yang mengalami kerusakan distop.Setelah motor bantu bekerja seperti biasa dua unit, Masinis II sebagai masinis jaga tidak langsung mengerjakan kerusakan pada motor bantu yang rusak tadi.Pada kapal-kapal, untuk membantu mengolah gerak menggunakan bow thruster dan untuk mengoperasikan Bow Thruster tersebut, kekuatan atau dayanya hampir sama dengan satu motor bantu. Pada saat kapal sedang mengolah gerak untuk sandar, tiba-tiba satu motor yang sedang beroperasi mengalami kerusakan pada salah satu cylindernya yang harus segera distop dan dengan sendirinya motor bantu yang beroperasi tinggal satu unit karena motor bantu yang rusak pertama belum diperbaiki/belum siap. Dengan hanya satu motor bantu yang bekerja, olah gerak kapal tidak memakai Bow Thruster. Dengan tidak memakai Bow Thruster dan dibantu kapal tunda, oleh gerak kapal terjadi kelambatan dengan demikian kelancaran operasional kapal terganggu.

\section{Menurunnya disiplin kerja}

Contoh dari kasus ini yaitu pada saat di pelabuhan saat kapal tiba akan mengadakan over houl. Motor induk dalam hal ini over houl cylinder head. Dalam mengerjakan pekerjaan ini Cief Engineer mengharapkan agar semua masinis harus bekerja memperbaiki motor induk tersebut. Namun sebagian masinis atau bawahan lain tidak mau bekerja dengan alasan pekerjaan tersebut di luar jam kerja, atau ingin turun ke darat untuk keperluan pribadi. Hal tersebut akan mengganggu kelancaran operasional kapal, karena bila sampai waktu keberangkatan kapal motor induk belum selesai dikerjakan, maka terpaksa keberangkatan kapal mengalami penundaan.

\section{Kurang lancarnya komunikasi}

Akibat kurang lancarnya komunikasi antara atasan dan bawahan penulis pernah 
mengalami pada saat kapal hendak melakukan Bunker, dimana sebagian yang berdinas tidak berada di tempat, karena informasi yang diterima masinis dua dari Cief Engineer tidak disampaikan kepada bawahan dengan jelas. Oleh karena itu Cief Engineer dalam memberi order kepada bawahan harus ditulis.Maka akibat dari kesalahan tersebut akhirnya Bunker baru dilaksanakan setelah orang-orang tersebut tadi kembali tiba di atas kapal.

\section{KESIMPULAN}

Produktivitas kerja Engine Room terganggu karena :

1. Ketrampilan ABK mesin menjadi kurang.

2. Disiplin kerja kurang

3. Komunikasi antara staf kamar mesin kurang lancar.

\section{DAFTAR PUSTAKA}

A. W. Widjaja, Drs, Administrasi Kepegawaian, Radar Jaya Offset 1995.

Buku "John C.Maxwell Judul Good Leaders Ask Great Questions.(Buku Terlaris Versi New York Times)

Buku "Keselamatan Pelayaran Dan Pencegahan Pencemaran Dari Kapal"Suatu Bahasan Konvensi Internasional Imo"Penyusun Pieter Batti.
Buku International Safety Management Code (Ism Code 2002)Oleh Capt.Hadi Supriyono,M.M,Mar.

Buku Karya "Jusak Johan

Buku Perawatan Mesin Oleh I.Suwandi Suparlan,Mme

H. Hadari, Prof. Dr., Kepemimpinan Mengefektifkan Organisasi, G.M. University Press, Yogyakarta 2003.Handoyo

Ir,Se,M,Min,M,Mar,E.Sistem

Perawatan Perbaikan Kapal.Penerbit Itb.

Ronald Heifetz, Lima Prinsip Kepemimpinan, Prestasi Pustaka, Jakarta 2005. 